\title{
OD GOLOTE INGRESOVE ODALISKE DO NAGOTE NA PODOBI S PLAKATA GUERRILLA GIRLS
}

Ključne besede: žensko telo, pogled, golota, spolna razlika, akt

Kako drugačna je nagota na ženskem aktu s plakata Morajo biti ženske nage, zato da bi prišle v Metropolitanski muzej? (Do Women Have to be Naked to Get into the Met. Museum?) skupine Guerrilla Girls od golote Ingresove Velike odaliske, na katero so se sicer sklicevale umetnice? Zastavljeno vprašanje se ne nanaša le na razlikovanje med pojmoma nagota in golota, kakor ga je v kontekstu akta uvedel umetnostni zgodovinar Kenneth Clark, temveč še bolj na spolno razliko glede načinov gledanja, dojemanja in prikazovanja golote ženskega telesa ob temi akta. Gre za dihotomijo med pogledom, ki se je ponavadi nahajal bolj na strani moškosti, in telesom, ki se je temu nasproti postavljalo bolj na stran ženskosti. Večino aktov zahodne likovne umetnosti so ustvarili moški umetniki, kajti ženskam je bilo vse do konca 19. stoletja zaradi moralnih razlogov onemogočeno ustvarjanje po golem modelu. ${ }^{1}$ Ženske so bile zaradi omejenih možnosti izobraževanja in

1 Na diskriminacijski aspekt v zvezi z nemožnostjo izobraževanja žensk na likovnih akademijah in onemogočanjem risarskega učenja po golem modelu je v svojem znanem eseju »Zakaj ni bilo velikih umetnic?" pokazala Linda Nochlin. Risanje in slikanje po živem modelu je bilo namreč v središču akademskega izobraževanja od osnovanja akademij v drugi polovici 16. stoletja pa vse do konca 19. stoletja. Obvladovanje človeškega telesa je bilo v tem času pomembno za nastanek vsakega dela, ki je težilo po veličini. Avtorica je ob tem pokazala na paradoksalno situacijo takratnih pravil spodobnosti, po katerih se je ženska, seveda iz nižjega razreda, kot model lahko gola razkazovala skupini neznanih moških, čeprav tudi to šele od druge polovice 19. stoletja dalje. Po drugi strani je bilo ženskam zaradi moralnih razlogov prepovedano prisostvovati pri aktivnem preučevanju in risanju modela, ne glede na to, ali je šlo za goloto moškega ali ženske (Nochlin, 2004, 9). 
zaradi popolne nemožnosti upodabljanja aktov že v osnovi diskriminirane tudi glede slikanja velikih mitoloških, bibličnih ali zgodovinskih tem. $\mathrm{Na}$ kakšne erotične motive $\mathrm{z}$ upodobitvami golih podob pa niso smele niti pomisliti, kaj šele da bi si jih tudi res drznile predstaviti na platnu.

Feministične teoretičarke so od sedemdesetih let 20. stoletja dalje začele opozarjati na dejstvo, da je bil pogled, ki je zaznamoval večino zahodne umetnosti, prevladujoče moški. Pogled, ki se je nahajal na strani moškosti, je določal vse aktivne gledalske vloge, in sicer od umetnika kot kreatorja umetniškega dela, in $\mathrm{s}$ tem najbolj aktivnega $\mathrm{v}$ verigi gledalcev, do vseh drugih predvidenih gledajočih subjektov, na primer naročnikov, umetnostnih zbiralcev, kupcev oziroma lastnikov umetniških del. Tudi v galerijah so moški dolgo predstavljali večinsko gledalstvo. Ženske, ki so skozi zgodovino na področju likovne umetnosti ostale diskriminirane v kontekstu izobraževanja in institucij ter posledično s tem tudi glede aktivnega ustvarjanja in profesionalnega vstopa $\mathrm{v}$ družbo, so bile do 20. stoletja omejene tudi v smislu pogleda. Redko so se nahajale v vlogah gledalk in še redkeje $\mathrm{v}$ vlogah umetnic, ki bi lahko ustvarjale dela, namenjena pogledu drugega. In vendarle je, vsem težavnim okoliščinam navkljub, v vsakem zgodovinskem obdobju obstajalo tudi nekaj redkih posameznic, ki so umetnostno zgodovino zaznamovale $\mathrm{z}$ ženskim pogledom. Ko govorimo o konceptu ženskega pogleda, moramo poudariti, da na spolno razliko bolj kot biološki faktorji vplivajo določeni družbeni dejavniki, pogojeni z vzgojo ter posebnimi kulturnimi in zgodovinskimi situacijami, v katerih so se v vsakem posameznem obdobju znašle ženske. Seveda je dela umetnic glede stila in tudi vsebin bolj smiselno primerjati $z$ deli njihovih kolegov posameznega obdobja ne glede na spol, na kar je opozorila že Linda Nochlin $(2004,9)$. Vsekakor pa so na umetniško produkcijo žensk skozi celotno umetnostno zgodovino vplivale tudi določene omejitve, ki so bile povezane prav z njihovim biološkim spolom. Poleg tega so obstajali žanri in motivi, ki so ostali umetnicam dolgo povsem nedostopni. Mednje sodi tudi akt in vse tematike, ki so se navezovale na golo človeško telo. Pristop ženskih umetnic $k$ temi telesa in še posebej h goloti se je zato skozi vsa zgodovinska obdobja dokaj razlikoval od pristopa njihovih moških kolegov.

Spolna razlika se ob temi akta po eni strani kaže $\mathrm{v}$ različnih pogledih moških in žensk na golo telo, po drugi pa v različni zastopanosti golih žen- 
skih in moških figur. Moško telo je bilo v kontekstu akta znotraj zahodne likovne umetnosti do 20. stoletja redko predstavljeno, čeprav so seveda obstajale tudi izjeme. ${ }^{2} \mathrm{Na}$ tem mestu se bom tudi sama omejila predvsem na žensko telo, ki je bilo v celotni tradiciji akta pogosteje izpostavljeno in je tako predstavljalo prevladujočo temo. John Berger je v delu Načini gledanja leta 1972 preko kritike objektiziranega golega ženskega telesa pokazal na enosmerno upodabljanje le-tega znotraj žanra, kakršen je v likovni umetnosti akt. Po njegovem so bile ženske vodilna, nenehno vračajoča se tema v eni kategoriji evropskega oljnega slikarstva: »Ta kategorija je akt. V aktih evropskega slikarstva lahko odkrijemo nekatere kriterije in konvencije, po katerih so bile ženske videne in presojane za poglede.«(Berger, 1972, 47).

$\mathrm{Na}$ delih večine moških avtorjev so bile ženske povečini pretirano izpostavljene na enostranski način, po katerem je bilo njihovo telo največkrat popredmeteno na ravni objekta, in sicer tako v primerih, ko so bile poniževane, kot tudi v nasprotnih primerih poveličevanja in čaščenja. Čeprav je bilo žensko telo v tradiciji akta nenehno upodabljano in skoraj pretirano eksploatirano, je bilo po drugi strani hkrati paradoksno vključeno v nekakšno tradicijo izključitve oziroma $v$ tiranstvo nevidnosti, kakor to imenuje Lynda Nead $(1992,60)$. Umetnice so temu nasproti poskušale pokazati na drugačne vrste obstoj ženskih teles ter s tem opozoriti na drugačno vrsto lastne prisotnosti in vidnosti v družbi. Znotraj feministične umetnosti sicer spet prevladujejo podobe telesa, vendar $\mathrm{z}$ bistveno razliko, ki je v tem, da žensko telo ni več razgaljeno na ponižujoč in seksističen način, temveč je golota predstavljena $\mathrm{z}$ novega zornega kota.

$\mathrm{V}$ pričujočem besedilu bom na spolno razliko glede prikazovanja in načina gledanja golote ženskega telesa ob temi akta pokazala skozi primerjavo Ingresove slavne slike Velika odaliska iz 19. stoletja in enega najbolj znanih feminističnih posterjev 20. stoletja, dela aktivistične umetniške skupine Guerrilla Girls ${ }^{3} \mathrm{z}$ naslovom Morajo biti ženske nage, zato da bi prišle v Me-

2 Moški akt je prevladoval le $\mathrm{v}$ antični umetnosti, ko je moško telo tudi sicer predstavljalo lepotni ideal. Kasneje so se moške figure kot erotični objekt pojavljale predvsem v delih homoseksualno orientiranih avtorjev, na primer Donatella in Michelangela, pa še to le dokler ni postala homoerotičnost obsojana in preganjana.

3 Guerrilla Girls se je imenovala feministična skupina anonimnih aktivističnih umetnic, ki so delovale v New Yorku v poznih osemdesetih in zgodnjih devetdesetih letih 20. stoletja. Pro- 
tropolitanski muzej? (slika 1). Besedilo plakata iz leta 1989 se v originalu glasi: »Do women have to be naked to get into the Met. Museum? Less than $5 \%$ of the artists in the Modern Art Sections are women, but $85 \%$ of the nudes are female.«

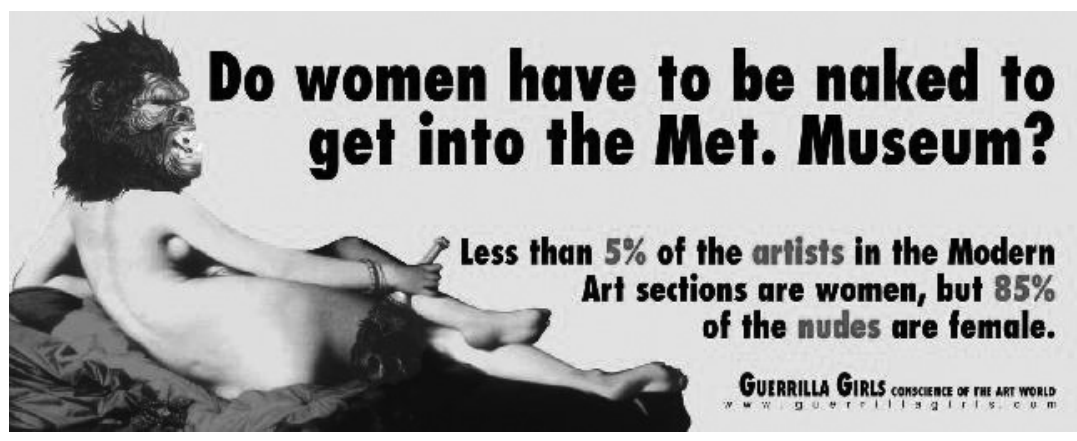

slika 1: Guerrilla Girls,

Morajo biti ženske nage, zato da bi prišle v Metropolitanski muzej?

(Do Women Have to be Naked to Get into the Met. Museum?), 1989

vir: http://www.shamelessmag.com/media/content/2008/02/guerrillagirls.jpg

Plakat s pomočjo osupljive statistike ironično razodeva, da je v modernih umetniških sekcijah med umetniki manj kot $5 \%$ žensk, hkrati pa je 85 $\%$ aktov ženskih. Gre za zgovorno dejstvo, ki razkrinkava absurdno razmerje glede prekomerne izpostavitve golih ženskih teles v prevladujoči tradiciji akta na eni strani in hkratne odsotnosti žensk kot umetnic v umetniškem svetu na drugi strani. Pretirano izpostavljenost ženskega telesa pogledu je v likovni umetnosti skozi zgodovino hkrati spremljal problem nezastopanosti in s tem nevidnosti žensk na področju umetnosti. To je tudi ena glavnih tem, s katero so se od sedemdesetih let prejšnjega stoletja ukvarjale teoretičarke in umetnice s tega področja.

testirale so proti institucionaliziranemu seksizmu in rasizmu, ki so ga prepoznale v muzejih, v galerijah, na razstavah, na gledaliških predstavah in v umetniških publikacijah. Leta 1985 so začele $\mathrm{z}$ razobešanjem posterjev okrog newyorškega Soha. Vizualno so bile prepoznavne po ogromnih črnih gumijastih gverilskih maskah. V svojih kampanjah so kot politična sporočila uporabljale posterje, kartice, letake in podoben grafični material. Prim. Chadwick $(1996,421)$. 
Poster predstavlja značilen primer feministične subverzije v umetniški praksi, ki so jo avtorice zasnovale tako preko vizualne podobe kot tudi preko jezikovnega sporočila. Z izpostavljeno figuro, sicer sposojeno iz tradicije akta, so razkrinkavale seksističen pomen golote $\mathrm{v}$ zvezi z ženskim telesom prevladujoče umetnostne zgodovine. Preko šokantnih statističnih dejstev so v besedilnem delu plakata pokazale na odsotnost žensk kot umetnic v javni sferi. S tem so opozorile na še vedno prevladujoče patriarhalne pozicije znotraj umetnosti, kjer je mesto ženske zvedeno bolj na razkazovano telo, ki predstavlja predmet pogleda, kot pa na vlogo aktivnega umetniškega subjekta.

Plakat tako izpostavlja in hkrati tudi že uspešno presega klasično binarno razmerje med spoloma v umetnostnem svetu, po katerem so moški opredeljeni kot subjekti in ženske kot objekti. Gre za nasprotje med tistimi, ki gledajo, delujejo, ustvarjajo, nadzorujejo ali posedujejo, ter tistimi, ki se razkazujejo, ki so gledane in ki se jih upodablja. Po takšni delitvi naj bi bili moški ustvarjalni in aktivni, ženske pa nedejavne, pasivne in popredmetene ali postvarele. John Berger je v tretjem poglavju dela Načini gledanja na osnovi analiziranja konkretnih primerov iz tradicije akta prvi pokazal na binarno opozicijo med moškimi, ki delujejo, in ženskami, ki se razkazujejo (Berger, 1972, 47).

Ena ključnih avtoric, ki je v sedemdesetih letih dalje razvijala binarizem med žensko kot podobo in moškim kot nosilcem pogleda, je bila filmska teoretičarka in umetnica Laura Mulvey. V svojem eseju "Vizualno ugodje in pripovedni film « (»Visual Pleasure and Narrative Cinema «) iz leta 1975 je objektivizacijo ženskega videza povezovala $z$ nezavednimi fetišističnimi praksami, ki so jih moški vključevali v umetniško produkcijo. Njena teorija se je s filmskega področja prenesla na velik del feminističnega raziskovanja, osredotočenega na vizualne umetnosti. Podobe žensk in njihovo središčno mesto $\mathrm{v}$ klasičnem hollywoodskem filmu je obravnavala $\mathrm{v}$ navezavi na psihoanalizo, s pomočjo katere je pokazala, da so določeni dogovori v popularnem pripovednem filmu strukturirani skozi patriarhalno nezavedno, kar postavlja ženske, ki so reprezentirane v filmih, za objekte »moškega pogleda «. ${ }^{4}$ Ob konceptih voajerizma, fetišizma in skopofilije je skozi analizo filmov izpostavila ženske like, ustvarjene za moški užitek v gledanju.

4 Laura Mulvey je ena prvih teoretičark, ki je začela uporabljati sintagmo "moški pogled «, danes sicer že paradigmatičen pojem za koncept pogleda $\mathrm{v}$ feministični teoriji. 
Tako kot je že Berger postavil opozicijo med moškim, ki deluje oziroma gleda, in žensko, ki je gledana, je tudi Laura Mulvey nasproti aktivnemu moškemu pokazala na pasivno žensko: »V svetu, ki temelji na spolni neuravnoteženosti, se je ugodje v gledanju razcepilo na aktivno/moško in pasivno/žensko. Določujoči moški pogled projicira svoje fantazije v žensko figuro, ki je oblikovana v skladu s tem.« (Mulvey, 2001, 278).

Tudi pri Lauri Mulvey se moški nahaja na strani pogleda, ženska pa na strani telesa. Če je moški lik »nosilec pogleda«, je ženska temu nasproti označena za »objekt moškega pogleda«. S tem se ženska figura kot razkazovana podoba oziroma erotični objekt umešča na stran telesa. Pomemben poudarek, ki ga je ob omenjeni dihotomiji izpostavila prav Laura Mulvey, sicer po sledi Freuda, je tudi nasprotje med aktivnostjo in pasivnostjo, pri čemer se spolna razlika kaže tako, da je moški pojmovan za aktivnega in ženska za pasivno.

Danes postaja sicer res že nekoliko dolgočasno ponavljati notorični binarizem, po katerem so bile ženske ob motivih akta ponavadi prikazane kot pasivni objekti v vlogah modelov, medtem ko so se moški na drugi strani nahajali v aktivnih vlogah umetnikov in gledalcev. Vendar pa ostajajo dalje aktualni primeri številnih mitov in prevladujočih umetniških motivov tradicionalne umetnostne zgodovine, ki postavljajo ženske na stran telesa in moške na stran pogleda. Prevladujoče figure čutnih Vener, kopajočih se Suzan, lepotic z ogledali in žensk ob toaletah, prostitutk, vampirk, deviških mladenk, usodnih žensk v stilu femme fatale ter vseh ostalih klišejskih podob žensk, ki so jih skozi več stoletij zahodne umetnosti vedno znova upodabljali moški, v veliki meri celo $v$ sodobnosti vplivajo na pojmovanje ženskih likov ob temi akta.

Omenjena opozicija predstavlja znotraj feministične kritike že kar nekakšno paradigmatično formulo za obravnavo vlog po spolu. Še vedno pogosto prisotno binarnost uspeva najbolje presegati tistim feminističnim umetnicam, ki se na svojih delih kritično zoperstavljajo pozicijam ženske kot zgolj objekta. To je odlično uspelo skupini Guerrilla Girls s plakatom Morajo biti ženske nage, zato da bi prišle v Metropolitanski muzej?, ki predstavlja kar najboljši primer aktivističnega delovanja v umetniški praksi, saj 
se zoperstavlja prevladujočim družbenim razmerjem, ki so tudi v umetniškem svetu jasno določena po spolu.

Avtorice so v poster kot vizualno parodijo vključile zamaskiran akt, ki so si ga sposodile iz klasične tradicije zahodnega slikarstva. Uporabile so podobo golega modela z znane Ingresove slike Velika odaliska (1814; slika 2).

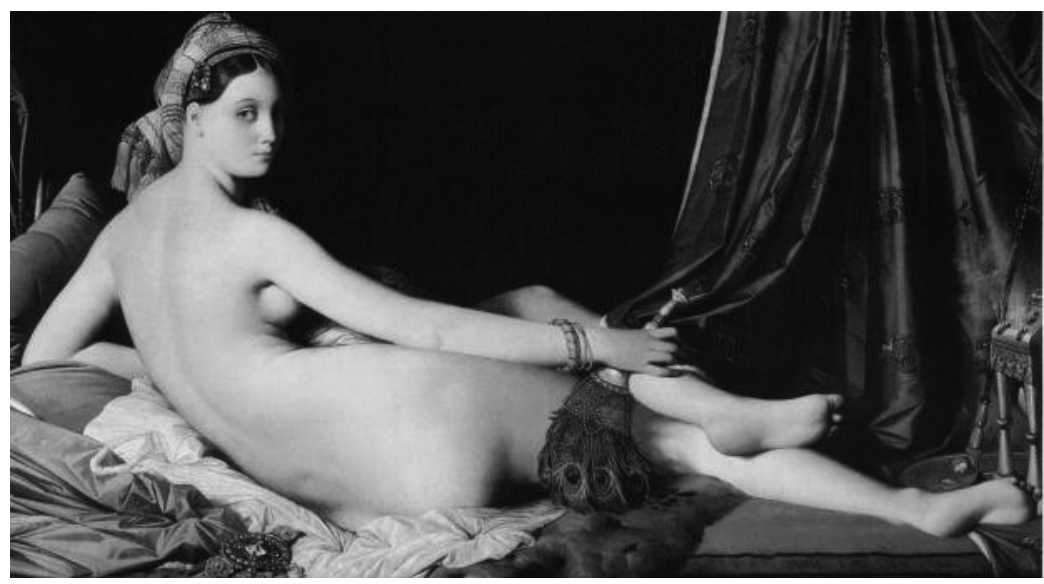

slika 2: Jean Auguste Dominique Ingres, Velika odaliska, 1814 vir: http://img.photobucket.com/albums/v201/VioletK/ingres-odalisque-louvre_1814_haremw.jpg

Jean Auguste Dominique Ingres je haremsko lepotico naslikal v ikonografski tradiciji klasičnih, napol ležečih golih Vener. Model je upodobil od zadaj, pri čemer je telo elegantno podaljšal. Nekateri kritiki so mu sicer očitali anatomsko deformacijo nemogoče razpotegnjenega hrbta in desne roke. Vendar je očitno, da si je slikar takšno nepravilnost telesa namenoma privoščil prav zaradi estetskega učinka, ki še bolj poudarja idealizirano lepoto naslikane ženske figure. Ingres je ženske akte pogosto upodabljal s hrbta. Tako je naslikal tudi Venero iz Valpincona / Veliko kopalko (1808) in kasneje Majhno kopalko (1826). Njegove podobe niso zaradi prikaza od zadaj nič manj erotične od tistih Vener, ki pogledom razkazujejo oprsja in v nekaterih primerih celo spolovila. Pravzaprav delujejo s svojo sramežljivo zadržanostjo, ki ne razkriva glavnih erotičnih predelov, še posebej vznemirljivo. $\mathrm{Na}$ Veliki odaliski se razen desne dojke, prikazane rahlo od zadaj in s strani, sicer neposredno ne vidi upodobljenkinih najbolj intimnih delov telesa. Ero- 
tično vzdušje nekoliko bolj poudarja orientalsko okrasje, ki jo obdaja. Leži na bogati posteljnini draperijsko nagubanih belih, zlatih in zelenih pregrinjal ter ob še bogatejših brokatnih zavesah modrikasto turkiznih odtenkov $\mathrm{v}$ ozadju. Okrašena je z zapestnicami, na glavi ima turban, $v$ roki pa drži bogato pahljačo iz pavovih peres. Pav naj bi še posebej v povezavi z žensko figuro predstavljal simbol nečimrnosti in napuha. ${ }^{5}$ Kasneje bom pokazala, kako je postala omenjena pahljača pomemben detajl v seksualnem smislu na reinterpretirani verziji pri podobi plakata skupine Guerrilla Girls.

Ingres je svoj model umestil v oddaljeno orientalsko vzdušje, podobno kot tudi nekatere druge svoje figure, na primer na slikah Odaliska in sužnja (1839) in na že omenjenih Venera iz Valpincona / Velika kopalka in Majhna kopalka, katerih sintezo predstavlja njegovo zadnje in najbolj poznano delo Turška kopel (1862), sicer ena najbolj erotičnih slik zahodne umetnostne zgodovine nasploh. Poleg poudarjenega erotičnega vzdušja služi orientalski kontekst tudi na sliki Velika odaliska predvsem za odmik upodobljenke od realnih žensk tedanjega okolja in časa, zaradi česar lahko omogoča večji in bolj brezskrben voajerski užitek ob pogledu na goloto idealizirane in nedostopne lepotice. Peter Webb meni, da je Ingres realnost želje pogosto prikrival $\mathrm{z}$ orientalskim kontekstom, $\mathrm{s}$ čimer se je zaščitil tako pred lastnimi kot tudi javnimi moralnimi pomisleki (Webb, 1975, 164). Tudi Uwe Fleckner je pisala o tem, kako se Ingres s svojimi golimi figurami ni želel izpostavljati pred kritiko, zato jih je zaščitil z legitimno orientalsko vsebino. Ob njegovih slikah harema in kopeli je poudarila, da so bila ta dela navdahnjena $\mathrm{z}$ orientalizmom 19. stoletja, ki se je pojavljal tako v literaturi kot tudi v likovni umetnosti. Njegovo Turško kopel je označila za portret imaginarnega Orienta, v katerega je bilo mogoče zaradi distance do tujega

5 Kot opozarja Tine Germ v knjigi Simbolika živali, se danes simbolika pava veže bolj na negativne lastnosti, čeprav naj bi imel pav pozitivne simbolne pomene v starejših mitologijah, $\mathrm{v}$ antiki in v srednjem veku. $\mathrm{V}$ grško-rimski mitologiji je bil pav nebeška ptica, posvečena kraljici neba, grški Heri oziroma rimski Junoni. Takrat je veljal za simbol nebeške lepote. V krščanski ikonografiji je pav prav tako predstavljal nebeško ptico, podobo rajske blaženosti in večnega življenja. Kot pravi avtor, so negativne vsebine prevladale razmeroma pozno. "Danes ob omembi pava najprej pomislimo na samovšečnost, nečimrnost, domišljavost, zagledanost vase ali nadutost. Sami negativni pomeni torej, ki pa vsi po vrsti izvirajo iz nedolžne navade pavov, da razkazujejo svoj čudoviti rep in poskušajo s tem pritegniti pozornost samic.« (Germ, 2006, 169). 
sveta prenesti evropske ideje, kar je lahko nadomeščalo pravico do slikanja erotičnih fantazij (Fleckner, 2000, 129).

Na sliki Velika odaliska gleda ležeča priležnica preko svoje desne rame proti gledalcu, tako da je njen obraz viden rahlo s strani, v klasično lepem profilu. Njen pogled je odsoten, medel in zdolgočasen, kot je brezizrazen in neoseben tudi celoten izraz na njenem obrazu. Kot večina Ingresovih naslikanih figur deluje hladno in nezainteresirano. Haremska priležnica naveličano čaka na moškega, kateremu mora biti njeno telo brezpogojno na razpolago za seksualne usluge. Zdi se povsem razosebljena in pasivizirana v popolnem pomenu te besede. Edino, kar počne, je to, da čaka. Gre za vrsto dejavnosti, ki pravzaprav sodi med nedejavnosti. Čakanje na moškega klienta oziroma v tem primeru na njenega haremskega gospodarja, zaradi katerega je nameščena $v$ ležečo pozo, je povsem primerljivo $\mathrm{z}$ dolgim poziranjem v vlogi umetniškega modela, namenjenega kasnejšim voajerskim užitkom gledalcev slike. Tako kot služi žensko telo $\mathrm{v}$ vlogi prostitutke moškemu za njegove seksualne užitke, je tudi v vlogi umetniškega modela namenjeno moškemu za uživanje $\mathrm{v}$ ogledovanju in s tem za razvnemanje domišljije. Naj gre za prostitutko ali umetniški model, v obeh primerih je žensko telo podobno posedovano, nadzorovano in na specifičen način uporabljeno za drugega. Moškemu je v celoti namenjena tudi ženska seksualnost. Iz večine aktov zahodne tradicije je mogoče razbrati, da žensko telo ni v oblasti samih žensk, temveč predvsem moških. In tudi ni naključje, da so bile ženske, ki so jih slikarji najemali za svoje modele, povečini prostitutke. One so bile edine, ki so lahko pozirale, kar kaže tudi na razredno razslojevanje in $\mathrm{s}$ tem na razlike $\mathrm{v}$ vlogah med samimi ženskami. V podobah ležečih Vener so umetniki tako pogosto slikali resnične prostitutke oziroma kurtizane, ki so jih sicer bolj ali manj idealizirali. Največkrat so jih upodobili v pozah, v katerih so zapeljivo čakale na svoje moške kliente. Takšne so poleg obravnavane Ingresove Velike odaliske tudi Tizianova Urbinska Venera (1538), Goyeva Gola Maja (1800-1805) in Manetova Olimpija (1863), če omenim samo najbolj znane podobe iz tradicije golih Vener. Naslikane so v držah, ob katerih je očitno, da čakajo na svoje stranke. Pri tem je vsaka od njih obrnjena proti svojemu predpostavljenemu, ne-upodobljenemu moškemu obiskovalcu, ki postane ob kasnejšem ogledovanju dela pravzaprav lahko sam opazovalec oziroma gledalec slike. 
V prevladujoči patriarhalno naravnani kulturi je bilo žensko telo očitno najpogosteje upodabljano predvsem za užitek moških gledalcev in lastnikov slik. Na to je opozoril tudi John Berger v delu Načini gledanja, kjer je skozi primere pokazal, kako so bile ženske $\mathrm{v}$ dolgi tradiciji meščanskega slikarstva prikazovane kot seksualno blago, ki je služilo za užitek moškega gledalca, zbiratelja in lastnika slik oziroma gledalca-lastnika [spectator-owner] slike, kakor ga je označi Berger z eno besedo. Moški je bil lastnik tako žensk kot slik. Hkrati je zato, ker se je zanj upodabljalo gola ženska telesa, veljal za glavnega protagonista slike, tudi če ni bil upodobljen na samem delu. Takšnega predpostavljenega moškega gledalca, proti kateremu so obrnjene zgoraj omenjene Venere, je Berger označil takole: „Glavni protagonist ni bil v povprečnem evropskem slikarstvu aktov nikdar naslikan. On je gledalec pred sliko, za katerega se predpostavlja, da je moški. Vse je usmerjeno proti njemu. Vse mora izgledati kot rezultat njegovega obstajanja tam. Zaradi njega figure dopuščajo svojo goloto. Toda on je po definiciji neznanec, ki ima svoja oblačila še vedno na sebi.« (Berger, 1972, 54).

Tudi Lisa Tickner meni, da seksualnost, prikazana ob temi akta, ponavadi ni pripadala upodobljenemu modelu, temveč lastniku slike. Kajti lastništvo naj bi v evropskem aktu veljalo za primarno in kot tako je bilo seveda na strani moških. Avtorica je pri obravnavi ženske seksualnosti ob politikah telesa poudarila tudi pomen besede erotika, ki naj bi v takšnem kontekstu pomenila zgolj »erotiko-za-moške«, in sicer celo v primerih, kjer je bila tema del lezbištvo ali ženska masturbacija (Tickner, 1987, 263).

Pri tem gre očitno za soodvisnost odnosov med družbenimi razredi in razmerji moči med spoloma, na kar je ob primerih kanonskih del modernističnega slikarstva pokazala Griselda Pollock v besedilu »Modernost in območja ženskosti«. Po njenem dela modernizma pogosto obravnavajo moško seksualnost in njen prepoznavni znak, ženska telesa. Avtorica je pokazala, da se številna modernistična dela ukvarjajo s seksualnostjo oziroma s potrošništvom, in sicer še posebej ob pogostih prizorih iz bordelov, v katerih moški svobodno iščejo užitke, ženske, ki tam delajo, pa so jim razredno podrejene (Pollock, 2004, 19).

Takšna enostranska situacija glede prikazovanja golote ženskega telesa in posledično tudi spolnih razmerij v seksualnosti je na delih zahodne umetno- 
sti prevladovala vse do 20 . stoletja. ${ }^{6}$ Glede reprezentacij ženske seksualnosti se je v evropski tradiciji marsikaj spremenilo šele v zadnjih desetletjih, ko so $\mathrm{k}$ temi golega telesa končno lahko svobodneje pristopile tudi same ženske. Vendar pa feministične umetnice golote niso navezovale zgolj na seksualnost tako kot večina moških, temveč so preko podob golega telesa pogledom razkrile pestro paleto različnih vsebin, vezanih na specifično ženske izkušnje, kakršne so na primer menstruacija, nosečnost, splav, rojevanje, materinstvo, bolezni, motnje hranjenja in podobno. Lastna telesa so tako prikazale na nove načine, preko katerih so podale tudi drugačno podobo ženske nasploh, saj so pokazale na vse tiste izkušnje v zvezi z ženskim telesom, ki so v preteklosti na delih moških avtorjev ostale nereprezentirane, nevidne, skrite, hkrati pa so lahko predstavljale celo neke vrste tabu. Nekatere avtorice so pogledom izpostavile telesa, ki večinoma niso bila v skladu s prevladujočim lepotnim idealom in zato do tedaj večinoma niso bila upodabljana. Kar naenkrat so postala vidna telesa žensk, ki so pred tem največkrat ostala onstran polja vidnega, skrita pred umetniškim pogledom in javnostjo nasploh.

Omenim naj le še, da so šle v zvezi z izpostavitvijo lastnih teles ob motivih seksualnosti najdlje lezbične avtorice. Sicer pa ostaja v zvezi z lezbičnimi podobami znotraj umetnostne zgodovine paradoksalno dejstvo, da so večino lezbičnih aktov do 20. stoletja tako ali tako ustvarili moški in ne same ženske. Seveda je ob tem jasno, da so bili erotični prikazi lezbičnih parov na delih umetnikov namenjeni bolj moškim voajerskim pogledom kot ženskim gledalkam. Poleg tega so nekatera dela nastala celo po naročilu, kot na primer ena najbolj znanih slik lezbičnega para, Speči ženski, naslovljena tudi Spanje, ki jo je leta 1866 naslikal Gustav Courbet. Delo, ki je nastalo namensko za užitek moškega gledalca, je naročil Khalil Bey, turški diplomat v Parizu, sicer znan umetniški zbiralec erotičnih del. ${ }^{7}$

6 John Berger opozarja, da golota v drugih, ne-evropskih tradicijah, na primer v indijski, perzijski, afriški in predkolumbijski, ni bila nikdar obsojana na takšen način kot v evropski umetnosti. Ob tem tudi omenja, da so $\mathrm{v}$ teh tradicijah drugače pristopali $\mathrm{k}$ temi seksualnosti. Na umetniških delih je bila seksualnost med dvema osebama prikazana enakovredno, tako da je bila ženska enako aktivna kot moški (Berger, 1972, 53).

7 Khalil Bey je leta 1866 plačal vstopnico za obisk Courbetovega ateljeja in najprej naročil sliko lezbičnega para Speči ženski, nato pa še sliko Izvor sveta, ki sicer predstavlja eno najbolj razvpitih erotičnih del zahodne umetnostne zgodovine. Prim. Nochlin $(1989,137)$ in Nochlin, L., Courbet Reconsidered, New York, 1988, 176. 
Že večkrat sem poudarila, da v preteklosti umetnice na svojih delih niso smele prikazovati nikakršne golote. $V$ času, ko je Courbet po naročilu drugega moškega lahko svobodno slikal dve goli speči lezbijki, si ženske niso mogle niti zamišljati, da bi lahko naslikale zgolj posamičen gol ženski akt, kaj šele dve goli telesi skupaj. Romaine Brooks je posamezne ženske figure, povečini lezbijke, lahko upodabljala šele pol stoletja po Courbetovi sliki razgaljenih ljubimk. Za prvo polovico 20. stoletja je bilo že to dovolj drzno, tako da je slikarka veliko pripomogla $k$ večji vidnosti lezbijk v družbi ne le $\mathrm{z}$ lastnim stilom in načinom življenja, temveč tudi z upodobitvami drugih lezbijk, pa čeprav večinoma oblečenih.

A vrnimo se nazaj k posterju Do Women Have to be Naked to Get into the Met. Museum?, na katerem so aktivistične umetnice glavo Ingresovega modela $\mathrm{z}$ neosebnim, naveličanim in celo otopelim izrazom obraza nadomestile s strašljivo gverilsko masko, ki je tudi sicer zaščitni znak skupine Guerrilla Girls. Z ogromno črno gumijasto glavo so zamaskirale in s tem hkrati tudi poudarile prav tisti del telesa, ki naj bi simbolično predstavljal razum in pozicijo subjekta, ter je zato ponavadi stereotipno pripisan moškosti. Za moške umetnike in gledalce je glava na ženski figuri pogosto predstavljala najbolj nepomemben del podobe, kar lahko opazimo po tem, kako so nekateri slikarji na ženskih aktih glavo prikazali kot manj poudarjen, komaj opazen ali celo neviden in s tem odvečen del telesa. Za vzbujanje užitka v gledanju, kar naj bi bil eden od glavnih namenov upodobljenih golih likov, je bila glava gledalcem ponavadi še najmanj zanimiva. Če so avtorice brezizrazen obraz Ingresove lepotice nadomestile $\mathrm{z}$ masko močno poudarjenega, agresivnega in grozljivega izraza, so $s$ takšno gesto očitno želele še posebej izpostaviti pomembnost ženske aktivne drže. Njihov akt se s svojim telesom pogledu drugega ne predaja več kot pasivna in nemočna lutka, temveč ga prav nasprotno opominja na status in vlogo žensk kot aktivnih subjektov v umetnostnem svetu. Lahko bi zapisala, da podoba na plakatu postane figura moči, ki ima stvari pod lastnim nadzorom oziroma v svojih rokah. In kaj pravzaprav res drži gverilska upornica v svoji elegantno podaljšani roki?

$\mathrm{Na}$ originalni Ingresovi sliki ima odaliska v roki pahljačo iz čudovitih pavjih peres, ki je kot okras lepo vidna in razpoznavna. Prav ta element je postal na plakatu Guerrilla Girls nekoliko zatemnjen, tako da se barvno ne vidi dobro in ne razpozna pisanega perja. Dobro je viden le svetlejši in 
nekoliko poenostavljen ročaj pahljače, ki v novi verziji dokaj očitno spominja na falično obliko, kar celotno podobo sprevrača $v$ povsem drugačen erotični kontekst. Ingresove slikarsko bogate barvne odtenke so avtorice na plakatu grafično obdelale in spremenile v črno-belo tiskarsko različico prvotne podobe $\mathrm{z}$ rahlo zaznavnim kožnim odtenkom. Barvna struktura je sicer za koncept sporočila na prvi pogled manj pomembna, čeprav vendarle vpliva na vidnost nekaterih detajlov podobe, na primer na omenjeni ročaj pahljače. Če je Ingresova ležeča upodobljenka, ob kateri je bilo povsem jasno, na koga čaka in komu mora biti njeno telo na voljo, jasno izražala klišejsko vlogo podrejene in pasivne ženske v seksualnosti, pa enaka figura na posterju takšnemu heteroseksističnemu kontekstu odločno nasprotuje. Sporočilo je ob tem povsem jasno. Ženska seksualnost je v prvi vrsti namenjena sami ženski. Čeprav akt tudi v novi različici leži v enaki pozi kot Ingresova pasivna in razpoložljiva figura, sta za učinek aktivne poze na novi podobi dovolj dve spremembi, in sicer glava z gverilsko masko in dvoumen ročaj v roki. Ob novi figuri je očitno, da mora imeti ženska lastno telo in $s$ tem predvsem lastno seksualnost povsem v svojih rokah oziroma pod lastnim nadzorom. Vendar pa je bil takšen poudarek na osvobojeni ženski seksualnosti za širšo javnost New Yorka v osemdesetih letih očitno še vedno preveč izzivalen, zato je plakat doživel cenzuro. Aktivistke so za poster najele oglasni prostor v newyorških avtobusih, kjer so plakati tudi viseli, vse dokler ni avtobusno podjetje razveljavilo njihove zakupne pogodbe, češ da je podoba, ki temelji na znani Ingresovi sliki, preveč sugestivna zaradi falične oblike ročaja pahljače. ${ }^{8} \mathrm{Ob}$ tem velja še posebej izpostaviti, da ni ob prepovedi izobešanja plakata nikogar zmotila sama golota ženske figure. Problematična je bila le oblika držala, ki je sicer podobna kot pri Ingresu, le da je manj okrašena in morda zaradi bolj enostavne oblike ter enobarvnosti res lahko videti bolj falična. Toda kakšen škandal bi šele bil, če bi reprezentirana figura v roki držala neki konkreten seksualni pripomoček in ne le okrasnega držala? Zanimivo je, da ročaj pahljače na Ingresovi sliki v 19. stoletju na gledalce ni deloval tako asociativno. Približek realnosti na posterju pa je konec 20. stoletja kar naenkrat postal preveč moteč. Za avtobusne potnike, sicer verjetno vajene najširše eksploatacije ženskega telesa v

$8 \quad$ Http://womhist.alexanderstreet.com/ggirls/doc13.htm. 
reklamnem oglaševanju in zahodni umetnosti nasploh, gol ženski akt $v$ javnem prevozu ni mogel predstavljati nič nenavadnega. Klasična idealizirana golota za voajerske gledalce ponavadi ni bila problematična. Za težavnega se je vedno znova izkazal vstop v realno. V zgodovini likovne umetnosti je problem vedno nastopil takrat, ko se je upodobitev preveč približala realnosti oziroma dejanskim ženskam $\mathrm{z}$ vsemi njihovimi individualnimi značilnostmi, kot se je to pokazalo v primeru Manetove Olimpije ali še prej Goyeve Gole Maje. Obe deli prikazujeta realni ženski z njunimi karakternimi portretnimi potezami, samozavestnih drž in izzivalnih pogledov ter brez kakšne mitološke, zgodovinske ali orientalske distance. V času, ko se je občinstvo pariškega Salona zgražalo nad Manetovo Olimpijo do te mere, da so morali delo pred napadalci zaščititi s posebno ograjo in dvema policajema, so se ti isti gledalci navduševali nad Cabanelovimi fantazijskimi akti morskih Vener in Ingresovimi oddaljenimi orientalskimi lepoticami. ${ }^{9}$ Manetova Olimpija je bila obsojana predvsem zato, ker je bilo žensko s slike mogoče resnično srečati na pariških ulicah. Goya, ki je po Goli Maji naslikal tudi oblečeno različico enake figure, Oblečeno Majo (1800-1805), pa se je moral zaradi obscenosti in nemoralnosti obeh del zagovarjati pred špansko inkvizicijo. Dve različni verziji enake figure, ki je bila enkrat upodobljena kot gola in drugič kot oblečena, kažeta na to, da so za slikanje aktov veljala jasna pravila glede prikazovanja golote že v preteklosti in da nagost s strani publike vendarle ni bila vedno tako enostavno sprejeta.

Pri aktu Guerrilla Girls sicer ni šlo za nobeno dejansko žensko, temveč za namig na svobodno žensko seksualnost. In očitno je bilo za širšo javnost že to preveč. Vsi zgoraj omenjeni primeri kažejo na pravo podobo hinavskega občinstva, ki nima težav $\mathrm{z}$ voajerskim uživanjem ob goloti idealiziranih lepotic, preoblečenih $\mathrm{v}$ takšne ali drugačne mitološke kontekste, problematično pa lahko postane, če se preko prikazane realne golote hkrati razstre tudi njihova želja. Več stoletij se je bilo možno brez težav naslajati nad goloto umetniških aktov evropskega oljnega slikarstva, zavito

9 Peter Webb omenja, da je bila na pariškem Salonu leta 1865 visoko spoštovana Cabanelova slika Rojstvo Venere (1865). Kljub pretkano naslikanim nogam figure je bila pred kritiko nemoralnosti zaščitena $\mathrm{z}$ mitološkim naslovom in konvencionalnim načinom slikanja. Sliko je kupil Napoleon III., ki je sicer surovo napadel Courbetove Kopalke leta 1853 in deset let kasneje tudi Manetov Zajtrk na travi. Prim. Webb $(1975,168)$. 
$\mathrm{v}$ tak ali drugačen, bolj mitološko ali bolj orientalsko obarvan kontekst. Že $\mathrm{v}$ renesansi je bilo mogoče voajersko uživati nad skoraj razprtimi mednožji nekaterih od Tizianovih Vener. Hkrati pa njegova sodobnica Sofonisba Anguissola na avtoportretu same sebe ni smela upodobiti niti z nasmeškom, kajti kaj takega že ni bilo več v skladu s strogimi moralnimi pravili glede vedenja plemenitih renesančnih dam. Medtem ko je na svojih slikah nadvse pazila, da je sebe in druge ženske slikala kot resnobne in olikane meščanke, so njeni moški kolegi začeli ne le razpravljati o lepoti in čutnosti, temveč tudi slikati konkretne erotične prizore. Kar poskušajmo si zamisliti, kako bi lahko kot ženska sredi 16. stoletja, ko so se gola telesa na erotičnih slikah začela prebujati v vsej dražestni seksualnosti, lahko naslikala glasbenico, ki igra na orgle in se čez ramo obrača k povsem golemu moškemu, pri čemer svoj pogled usmerja v njegovo mednožje? To si je Tizian seveda lahko privoščil kot nekaj najbolj samoumevnega. ${ }^{10}$ Anguissolina glasbenica je bila lahko predstavljena le kot uglajena plemkinja, ki igra na kakšen klavikord ali spinet, saj je bilo v skladu s humanističnimi ideali dobre vzgoje zaželeno, da obvladuje tudi nekaj glasbene veščine. ${ }^{11}$ Seveda se zdi absurdna že sama pomisel na to, da bi si slikarka kot ženska sploh drznila naslikati moški akt, kaj šele, da bi ga umestila med bele rjuhe in ga prikazala, ko si z roko v stilu sramne geste prekriva svoj ud in se smehlja proti voajerskim gledalkam. $\mathrm{Na}$ takšne feministične parodije je bilo potrebno počakati še nekaj stoletij.

Za konec si poglejmo še izrazoslovno plat plakata, ob katerem lahko med drugim opazimo tudi razliko med izrazoma »to be naked « in »nudes«, kar je možno povezati $\mathrm{z}$ razlikovanjem med pojmoma »nagost « in »golost «. Omenjeno distinkcijo je uvedel umetnostni zgodovinar Kenneth Clark v knjigi Akt: Študija idealne oblike. Avtor je razločevanje med pojmoma »nagota« (»nakedness«) in "golota« (»nudity«), ki jo ponuja angleški jezik, oziroma med »biti nag« (»to be naked») in »biti gol« (»to be nude«) označil takole: »Biti nag pomeni biti prikrajšan za oblačila, pri čemer že sama beseda namiguje na nekakšno zadrego, ki jo večina od nas čuti v takšnih

10 Pri tem mislim na Tizianovo delo Venera $z$ orglarjem (1550), ki ga je slikar tako kot vsa svoja uspešna erotična dela naslikal večkrat.

11 Sofonisba Anguissola se je na svojih avtoportretih pogosto prikazala v vlogi glasbenice. Za mlade ženske je bilo tedaj glasbeno znanje na splošno precej bolj cenjeno od obvladovanja slikarske veščine, zato so se renesančne umetnice raje kot slikarke upodabljale ob glasbilih. 
okoliščinah. Po drugi strani pa beseda golota nima nikakršnega neudobnega prizvoka.«(Clark, 1956, 23). Pri Clarku gre za razliko med nagimi telesi, ki so brez oblačil in so tako na nek način nezaščitena, ter golimi telesi, ki so oblečena skozi umetnost. Akt naj bi predstavljal preoblikovano telo, telo v reprezentaciji, telo, ki je oblečeno v umetnosti. Gre za estetsko preobrazbo konkretne nagosti telesa v idealizirano goloto akta, ki pri Clarku predstavlja, kot zapiše Lynda Nead, premestitev od dejanskega k idealu oziroma od neoblikovane, materialne snovi v idealno umetniško obliko (Nead, 1992, 14).

Za motiv akta je že tako ali tako značilno, da prikazuje golo telo, zato je sopomenska raba, ki jo omogoča angleščina, nekako smiselna. Pri plakatu Guerrilla Girls je beseda »naked « uporabljena v kontekstu nagih žensk, torej žensk brez oblačil, pri čemer gre očitno za opozarjanje na stereotip, da pridejo ženske do institucij lahko predvsem preko lastnih golih teles. Po drugi strani so ženske $\mathrm{v}$ umetnostnih ustanovah večinoma prisotne le kot podobe, kot gole figure na umetniških delih, na kar kaže tako vizualni kot jezikovni del plakata. Na to se nanaša tisti del sporočila, ob katerem so avtorice uporabile besedo »nude«, za katero angleščina ponuja sopomensko rabo v smislu akta kot umetnostnega motiva in tudi kot nekoga, ki je gol.

Clarkovo razlikovanje med nagoto in goloto bi lahko prenesli na razločevanje med golo figuro z Ingresove slike in predelano golo figuro s plakata Guerrilla Girls, ki je bližje pojmu nagosti. Lahko bi rekli, da je ob Ingresovi podobi idealizirane lepotice golota predstavljena kot nekakšna oblika obleke. Pri odaliski ne gre za nikakršno konkretno nagost določene realne ženske, ki bi jo slikar realistično prenesel od modela k figuri na platno. Namesto tega je slikar še posebej poskrbel za idealizacijo podobe tudi s tem, da je modelu na sliki elegantno podaljšal hrbet. Njegova upodobljenka je idealizirana domišljijska podoba, ki zaradi tega, ker nima na sebi nobene obleke, ne kaže prav nikakršnega sramu. Po drugi strani njena golota zaradi idealizirane oblike telesa in celotne umestitve $\mathrm{v}$ fantazijsko zamišljen orientalski kontekst tudi ne more vzbujati nikakršnega občutka krivde glede voajerskega opazovanja ne pri umetniku ne pri kasnejšem predvidenem moškem gledalcu. Potemtakem ni prav nič moralno sporna, saj je idealizirana do te mere, da verjetno ni imela več kaj dosti skupnega z izvornim modelom.

$\mathrm{V}$ čem je torej glavna razlika med goloto Ingresove odaliske in goloto na reinterpretiranem aktu, ki so ga na svojem plakatu uporabile Guerrilla 
Girls? Čeprav gre na obeh delih za podobo enake gole ženske figure, vidne od zadaj, je vendarle očitna razlika v celotnem kontekstu, v katerega je akt umeščen. Bistvena razlika nastopa $\mathrm{v}$ vsebinskem načinu podajanja golote in posledično s tem tudi v načinu gledanja oziroma dojemanja razkrite golote. Pri Ingresovi podobi je očitno, da je slika nastala za voajerski pogled predpostavljenega moškega gledalca. Feministične umetnice so ta isti akt reinterpetirale tako, da so preko tematike golote pokazale na problematiko $\mathrm{v}$ zvezi z izpostavljanjem nagosti ženskih teles ob motivu akta in v umetniškem svetu nasploh. Hkrati so aktivistično opozorile tudi na odsotnost žensk kot aktivnih udeleženk na področju umetnosti, in sicer še posebej na njihovo neprisotnost znotraj umetnostnih ustanov. Njihova podoba ni nastala z namenom vzbujanja kakršnegakoli voajerskega ugodja ob pogledu na podolgovato telo lepotice, prikazane s hrbtne strani v napol ležečem položaju, temveč ravno nasprotno, kot kritika uveljavljenega načina gledanja, dojemanja in uporabljanja ženskih teles za upodabljanje na umetniških delih. Pogled na razgaljen ženski hrbet nikakor ne more nuditi užitka voajerskim gledalcem ob hkratnem pogledu na grozečo gverilsko masko. V novem kontekstu kaže podoba žensko figuro, ki ni več pasivna, temveč ima lastno telo in s tem tudi lastno seksualnost pod svojo oblastjo. Na plakatu poleg vizualnega dela pozornost hkrati pritegnejo tudi poudarjene črke jezikovnega dela sporočila, ki ironično poudarja paradoksno situacijo v zvezi z nagostjo $\mathrm{v}$ umetniškem sistemu. Umetnice so $\mathrm{k}$ imenu skupine Guerrilla Girls dodale tudi pripis »Conscience of The Art World«. Delovale so torej kot »vest umetniškega sveta«. S svojim delom so v vlogi vesti poskušale vzbuditi občutek za moralno odgovornost glede položaja žensk v umetnostnih ustanovah. Hkrati so potrkale tudi na vest tistih, ki ženske vidijo in pojmujejo le v kontekstu zunanjega videza oziroma golote njihovih teles. Njihova podoba ni bila namenjena le ozkemu segmentu predpostavljenih moških gledalcev, kakor je to sicer veljalo v tradiciji akta, ali specifično orientiranim feminističnim gledalkam, temveč je poster $\mathrm{z}$ močno poudarjeno aktivistično noto poskušal nagovarjati širše občinstvo tudi zunaj umetnostnih in strokovnih inštitucij, na kar kaže njihov vstop v oglaševalsko področje javnega prostora. Avtorice so $\mathrm{z}$ opozarjanjem na problematiko nevidnosti žensk v javni sferi umetnostnega sveta in hkratno prekomerno izpostavljenostjo golega ženskega telesa poskušale ozaveščati tudi najširšo publiko. 
Po drugi strani se v času, ko se ženske lahko že nekaj časa enakopravno izobražujejo na likovnih akademijah in ko naj bi bile tudi v širši družbi obravnavane vse bolj enakovredno, pogosto zastavlja vprašanje, zakaj so $\mathrm{v}$ umetniški praksi sploh še potrebne takšne radikalne feministične geste, kakršne izvajajo članice skupine Guerrilla Girls. Res je, da so danes umetnicam dostopne vse tematike, tudi tiste, ki se navezujejo na gola telesa, in vsaj zdi se, da je celo v zvezi s seksualnostjo že padla večina tabujev. Vendar pa ostaja spolna razlika na področju umetnostnega sistema, tako kot tudi pri vseh drugih dejavnostih, še vedno dokaj očitna. Na to dovolj zgovorno kaže tudi primer ene od zadnjih akcij skupine Guerrilla Girls. Avtorice so leta 2005, ko so razstavljale na beneškem bienalu, ${ }^{12}$ na posterju Morajo biti ženske nage, zato da bi prišle v Metropolitanski muzej?, ki še vedno velja za enega njihovih najbolj provokativnih del, nekoliko predrugačile statistične podatke. Po mnogih letih svojega delovanja so znova preštele razmerje umetnic in umetnikov v modernih in sodobnih umetnostnih sekcijah Metropolitanskega muzeja v New Yorku, ker so bile prepričane, da so se vmes stvari spremenile. A namesto tega so presenečeno ugotovile, da je bilo zastopanih celo manj umetnic kot pred šestnajstimi leti. Zato so na posodobljenem plakatu statistiko petih spremenile $\mathrm{v}$ še bolj ponižujoče tri odstotke umetnic: »Less than 3\% of the artists in the Modern Art Sections are women, but $83 \%$ of the nudes are female. « In kot ob tem same pravijo na svoji spletni strani: "Kar uganite, zakaj še vedno ne moremo odvreči mask! «13 Sama menim, da so tovrstne aktivistične poteze še vedno nujne,

12 Naj omenim, da je bil poster Do Women Have to be Naked to Get into the Met. Museum? leta 2005 razstavljen tudi na 51. beneškem bienalu sodobne umetnosti. Skupini Guerrilla Girls je bila namenjena ena cela galerijska sobana v razstavnih prostorih Arzenala. To najstarejšo bienalsko prireditev s področja sodobne umetnosti sta takrat prvič v 110-letni bienalski zgodovini zasnovali ženski, in sicer Maria de Corral in Rosa Martinez. Seveda je pomenljivo že samo dejstvo, da sta bili prvič izbrani dve umetniški vodji. Vsekakor je to bistveno vplivalo na samo zasnovo bienala, na katerem ni bilo nikdar prej zastopanih toliko ženskih umetnic. Učinki so bili očitni tudi ob podeljevanju nagrad, saj so kar tri od štirih možnih nagrad prejele ženske (nagrado zlati lev za življenjsko delo je dobila ameriška feministična umetnica Barbara Kruger). Po drugi strani se zdi presenetljivo, da je umetniška stroka za kaj takega postala zrela šele leta 2005, čeprav je bil feminizem na področju vizualne umetnosti na zahodu na višku svojega razcveta v sedemdesetih in osemdesetih letih 20. stoletja. To samo kaže na dejstvo, kako počasi se v kontekstu enakopravnosti med spoloma in večje vidnosti ter zastopanosti umetnic $\mathrm{v}$ javni sferi, spreminja tudi širša družba.

13 Http://www.guerrillagirls.com/posters/getnakedupdate.shtml. 
in sicer ne le zaradi neenakih možnosti in neenakopravne zastopanosti obeh spolov na področju umetnosti, temveč še bolj zaradi opozarjanja na vsebinske razlike pri obravnavanju del umetnic in umetnikov ter dvojnih meril, ki veljajo glede razkazovanja golote. Kajti še vedno se nahajamo v svetu pretirano izpostavljene golote popredmetenih ženskih teles, ki velja za neproblematično, medtem ko lahko po drugi strani razlog za cenzuro predstavlja že nedolžna falična oblika v ženski roki.

\section{LITERATURA}

BAHOVEC, Eva D., »Žensko telo in oblast v mediju vizualnega«, Delta, 1995, 3-4.

BERGER, John, Ways of Seeing, British Broadcasting Corporation in Penguin Books, London in Harmondsworth, 1972.

CHADWICK, Whitney, Women, Art, and Society, Thames and Hudson, London, 1996.

CLARK, Kenneth, The Nude: A Study of Ideal Form, Doubleday Anchor Books, New York, 1956.

FLECKNER, Uwe, Masters of French Art: Jean-Auguste-Dominique Ingres: 1780-1867, Könemann, Cologne, 2000.

GERM, Tine, Simbolika živali, Modrijan založba, Ljubljana, 2006.

LUCIE-SMITH, Edward, Erotizam u umetnosti zapada, Svet umetnosti, Jugoslavija, Beograd, 1973.

MULVEY, Laura, »Vizualno ugodje in pripovedni film«, v: Vidmar, Ksenija H. (ur.), Ženski žanri: Spol in množično občinstvo v sodobni kulturi, Zbornik besedil medijskih študijev in feministične teorije, ISH - Fakulteta za podiplomski humanistični študij, Ljubljana, 2001.

NOCHLIN, Linda, Women, Art, and Power and Other Essays, Thames and Hudson, London, 1989. 
NOCHLIN, Linda, "Zakaj ni bilo velikih umetnic?«, Likovne besede, Teoretska priloga: Feministična teorija umetnosti, izbrani teksti, 2004, 69-70, 2-15.

NEAD, Lynda, The Female Nude: Art, Obscenity and Sexuality, Rouetledge, London in New York, 1992.

PARKER, Rozsika \& POLLOCK, Griselda, Framing Feminism: Art and the Women's Movement 1970-85, Pandora, An Imprint of Harper Collins Publishers, London, 1987.

POLLOCK, Griselda, »Modernost in območja ženskosti«, Likovne besede, Teoretska priloga: Feministična teorija umetnosti, izbrani teksti, 2004, 69-70, 16-35.

TICKNER, L., »The body politic: female sexuality and women artists since 1970«, v: Parker, R. in Pollock, G., Framing Feminism: Art and the Women's Movement 1970-85.

WEBB, Peter, The Erotic Arts, Secker \& Warburg, London, 1975. 


\section{FROM THE NUDITY OF INGRE'S ODALISQUE TO THE NAKEDNESS OF THE GUERRILLA GIRLS POSTER}

Keywords: woman's body, view, nudity, sex difference, nude

\section{Abstract}

This article is based on sex difference in ways of seeing, perceiving, and representing nudity and the theme of the nude. A sex difference is seen in different representations of female and male nudes on the one hand, and on the other hand in the different ways men and women view the naked body. Until the twentieth century, male figures were represented less often than female images. Female nudes have been the main subject in the tradition of western painting. This reflects the sexual dichotomy between viewing, more connected with the male side, and the body, more connected with the female side.

Sex differences are highlighted through a comparison of Ingre's famous nineteenth-century painting Grande Odalisque and one of the most popular feminist posters of the twentieth century: Do Women Have to be Naked to Get into the Met. Museum? by the activist artistic group Guerrilla Girls. The question is how the nakedness of the female nude in the poster by Guerrilla Girls differs from the nudity of Ingre's Odalisque, to which the women artists referred. The Guerrilla Girls work indicates how it is possible to oppose the established binary structures of men as subjects in the roles of artists, spectators, collectors, and owners of artworks on the one hand, and women as objects in the roles of passive and nude models on the other. 